\title{
Adoption of Oral Disease-Modifying Treatments for Multiple Sclerosis in Europe and the United States between 2012 and 2015
}

\author{
Siva Narayanan ${ }^{1}$, Simone Gabriele ${ }^{2}$, Joanna White $^{3}$, Emily Hautamaki $^{4}$ \\ ${ }^{1,4}$ Ipsos Healthcare, Washington, DC, USA \\ ${ }^{2,3}$ Ipsos MORI, London, UK \\ Corresponding Author \\ Siva Narayanan \\ SVP and Global Head, Global Evidence, Value and Access, Ipsos Healthcare \\ 2020 K St NW, Suite 410, Washington, DC 20006 \\ Tel. +1 2032971208 \\ siva_narayanan[at]verizon.net
}

\begin{abstract}
A retrospective chart review of multiple sclerosis (MS) patients in EU (UK/France/Germany/Italy/Spain) and the United States (US)was conducted to evaluate adoption of oral disease-modifying treatments (DMTs) for MS, and corresponding patient disease characteristics. In 2012 and 2015 respectively, 3490 (EU:2479; US:1011) and 3732 (EU:2724; US:1008) charts were abstracted. Use of oral DMT increased (EU:11.3-35.6\%; US:9.2-40.0\%) between 2012-2015 with the largest increase observed in first line therapy, and the percentage citing oral administration or patient decision as reasons for choice of DMT increased over this time period. Among oral DMT users, the proportion with moderate/severedisease severity (EU:74.8-45.5\%; US:64.4-48.8\%) and mean Expanded Disability Status Scale (EDSS) scores (EU:3.6-2.7; US:3.2-3.0) decreased between 2012-2015, while remaining stable for non-oral DMT users.Further research is warranted to evaluate the drivers behind the observed trends and impact of individual DMTs on patient outcomes.
\end{abstract}

Keywords: Multiple sclerosis, disease modifying treatments, oral, disease severity, retrospective chart review

\section{Introduction}

Multiple sclerosis (MS) is understood to be, at least in part, an autoimmune disease of the central nervous system [1]. The disease causes demyelination, resulting in an array of symptoms, including fatigue, depression, neuromuscular problems, pain, sleep disorders, bowel and bladder problems, vision problems, and sexual dysfunction [2].

Traditional management of MS often involves frequent selfinjection with disease-modifying treatments (DMTs) [2]. While the use of oral DMTs is increasing, DMTs administered via injection still predominate the first line treatments for MS [3]. Patients with MS face many barriers to adherence to treatment, including cognitive impairment and physical disability impairing their ability to self-inject, perceived lack of efficacy, adverse events, inconvenience, needle phobia, and uncertainty about the injection technique $[4,5]$. Patients have reported dissatisfaction with selfinjection; in a recent multinational study, among patients using vials and syringes to self-inject, only $23 \%$ reported being "very satisfied" with their current injection method. ${ }^{5}$ In another multinational study, $25 \%$ of patients were found to be non-adherent to DMTs, with nearly one-third citing injection-related reasons [6]. In the same study, adherent patients reported better quality of life than non-adherent patients [6]. A large database analysis of MS patients in the US found that increasing adherence was associated with a reduced healthcare resource utilization associated with inpatient or emergency room visits, fewer days of work loss, and reduced direct and indirect costs [7].
There are currently three oral DMTs for MS available in Europe (EU) and the United States (US) - fingolimod, teriflunomide, and dimethyl fumarate, which became available between 2010 and 2014. This research sought to quantify the uptake of oral drugs among patients with MS in EU and the US.

\section{Material and Methods}

The study consisted of a multi-center, retrospective chartreview of MS patients inEU [France, Germany, Italy, Spain,the United Kingdom (UK)] and the US, conducted between October and December of 2012 (Q4 2012) and again between April and June 2015 (Q2 2015). Healthcare providers (HCPs) practicing in hospitals or private practices were recruited from a large commercial panel to be geographically representative in each country.

Online HCP panels offer a robust sample of target population for research involving retrospective chart review and cross-sectional survey designs via geo-dispersion sampling (whereby, stakeholders are recruited from a wide selection of clinics/hospitals in a given geography, with each clinic/hospital contributing almost equal number of study samples); this methodology avoids clinic/HCP sampling biases occasionally associated with selection/use of only limited set of institutions, especially in research related to widely prevalent disease(s).

HCPs in this study wereprimarily neurologists (MS nurses were included in the UK) who had been practicing for at 


\section{International Journal of Science and Research (IJSR) \\ ISSN (Online): 2319-7064 \\ Index Copernicus Value (2013): 6.14 | Impact Factor (2015): 6.391}

least three years, who see at least $15 \mathrm{MS}$ patients per month, write more than one prescription for a disease-modifying treatment (DMT) per month, and are primarily responsible for the long-term treatment decisions of their MS patients.

At both time points, HCPs completed the chart review for their next ten consecutive study-eligible MS patients that they saw for a consultation, including seven patients with relapsing-remitting MS (RRMS), two with secondaryprogressive MS (SPMS), and one with clinically isolated syndrome (CIS). The chart review collected de-identified anonymizeddata on patient demographics and clinical status, diagnostic and disease severity assessments (Incl. Expanded Disability Status Scale (EDSS) score, as well as MS disease severity on a scale of mild/moderate/severe and MS activity on a scale of non-active/active/highly-active - perphysician clinical judgment), and patient treatment patterns. This study consisted of secondary data collection (retrospectively); the physician participants were de-identified (pseudonymous) and the data abstracted by these physicians were based on anonymized patient records. The patient themselves were not directly involved in the study in any manner. As such, an ethics review was not required for the use of this research design in the concerned settings; further, only physicians who did not require a local ethics review for implementing this study (based on the de-identified anonymous nature of data collection) participated in this study.

Analysis was conducted by region (EU \&US). Descriptive and bivariate statistics were generated. Comparisons were made between the two time points of 2012 and 2015. Statistical differences were assessed using chi-square tests for categorical variablesor t-tests for continuous variables; $p$ values of $<0.05$ were considered significant in all analyses.

\section{Results}

In 2012, 245 HCPs in EU and 101 HCPs in the US abstracted data for 2479 and 1011 patients, respectively; in 2015, 271 HCPs in EU and 100 HCPs in the US abstracted data for 2724 and 1008 patients, respectively.

\section{Patient demographics and clinical characteristics}

At both time points and in both regions, approximately twothirds of the patients were female. The average age was about 40 years. Over half of the patients were considered to have mild MS severity or non-active disease and on average, patients had $<1$ relapse in last 12 months. The majority of the patients were currently on treatment for MS; specifically $69.8 \%$ and $71.9 \%$ in EU in 2012 and 2015, respectively, and $78.4 \%$ and $80.9 \%$ in the US in 2012 and 2015 , respectively. (Table 1)
Table 1: Patient demographics and clinical characteristics

\begin{tabular}{|c|c|c|c|c|}
\hline & \multicolumn{2}{|c|}{ Europe } & \multicolumn{2}{|c|}{ USA } \\
\hline & 2012 & 2015 & 2012 & 2015 \\
\hline Total Patient Sample & 2479 & 2724 & 1011 & 1008 \\
\hline $\begin{array}{c}\text { Gender } \\
\text { Female } \\
\text { Male }\end{array}$ & $\begin{array}{l}65.1 \% \\
34.9 \%\end{array}$ & $\begin{array}{l}64.5 \% \\
35.5 \%\end{array}$ & $\begin{array}{l}68.1 \% \\
31.9 \%\end{array}$ & $\begin{array}{l}69.2 \% \\
30.8 \%\end{array}$ \\
\hline Age & \begin{tabular}{|c|}
38.3 \\
years
\end{tabular} & \begin{tabular}{|c|}
39.1 \\
years
\end{tabular} & \begin{tabular}{|c|}
42.3 \\
years
\end{tabular} & $\begin{array}{c}42.3 \\
\text { years }\end{array}$ \\
\hline $\begin{array}{l}\text { Type of MS } \\
\text { Clinically Isolated } \\
\text { Syndrome } \\
\text { Relapsing-remitting MS } \\
\text { Secondary-progressive MS } \\
\end{array}$ & $\begin{array}{l}10.3 \% \\
69.7 \% \\
20.0 \%\end{array}$ & $\begin{array}{l}10.1 \% \\
69.9 \% \\
20.0 \%\end{array}$ & $\begin{array}{l}10.0 \% \\
70.0 \% \\
20.0 \%\end{array}$ & $\begin{array}{l}10.0 \% \\
69.9 \% \\
20.0 \%\end{array}$ \\
\hline $\begin{array}{l}\text { MS severity* } \\
\text { Mild } \\
\text { Moderate } \\
\text { Severe }\end{array}$ & $\begin{array}{c}52.3 \% \\
38.2 \% \\
9.5 \%\end{array}$ & $\begin{array}{c}54.1 \% \\
36.4 \% \\
8.3 \%\end{array}$ & $\begin{array}{c}52.8 \% \\
37.8 \% \\
9.4 \%\end{array}$ & $\begin{array}{c}55.2 \% \\
37.0 \% \\
6.5 \%\end{array}$ \\
\hline $\begin{array}{l}\text { MS activity* } \\
\text { Non-active } \\
\text { Active } \\
\text { Highly active } \\
\end{array}$ & $\begin{array}{c}54.8 \% \\
41.3 \% \\
3.9 \% \\
\end{array}$ & $\begin{array}{c}53.0 \% \\
40.3 \% \\
6.0 \%\end{array}$ & $\begin{array}{c}50.9 \% \\
45.1 \% \\
4.0 \% \\
\end{array}$ & $\begin{array}{c}52.2 \% \\
44.3 \% \\
3.0 \% \\
\end{array}$ \\
\hline $\begin{array}{l}\text { Current EDSS } \\
\text { score }(\text { range }=0-10, \text { higher } \\
\text { scores indicate greater } \\
\text { disability) } \\
0.0-4.0 \\
4.5-7.0 \\
7.5-10.0 \\
\text { Mean } \\
\text { Unknown/not assessed }\end{array}$ & $\begin{array}{l}60.2 \% \\
27.9 \% \\
7.7 \% \\
2.90 \\
2.4 \%\end{array}$ & $\begin{array}{c}62.0 \% \\
27.5 \% \\
6.5 \% \\
2.83 \\
4.0 \%\end{array}$ & $\begin{array}{c}50.8 \% \\
26.6 \% \\
5.6 \% \\
2.73 \\
16.9 \%\end{array}$ & \begin{tabular}{|c|}
$50.3 \%$ \\
$26.5 \%$ \\
$4.9 \%$ \\
2.74 \\
$18.4 \%$
\end{tabular} \\
\hline $\begin{array}{l}\text { Average number of relapses } \\
\text { suffered in last } 12 \text { months }\end{array}$ & 0.63 & 0.67 & 0.62 & 0.70 \\
\hline $\begin{array}{l}\text { Current treatment Status } \\
\text { Treatment-naïve } \\
\text { Currently treated } \\
\text { Discontinued }\end{array}$ & $\begin{array}{c}20.7 \% \\
69.8 \% \\
9.6 \%\end{array}$ & $\begin{array}{l}17.8 \% \\
71.9 \% \\
10.3 \%\end{array}$ & $\begin{array}{c}14.1 \% \\
78.4 \% \\
7.4 \%\end{array}$ & $\begin{array}{c}11.9 \% \\
80.9 \% \\
7.2 \%\end{array}$ \\
\hline
\end{tabular}

*per physician"s clinical judgment; ${ }^{\wedge}$ EDSS: Expanded Disability Status Scale;

\section{Initiation, switching, and discontinuation of DMTs}

Among currently treated patients, by 2015 , the time between MS diagnosis and initiation of a DMT decreased from an average of 12.4 months to 8.0 months in EU $(p<.01)$, and from 10.0 months to 4.6 months in the US $(p<.01)$, compared to 2012, indicating that patients are being initiated on DMTs earlier. Among patients on their first line DMT, the difference is even greater, from 13.6 months to 8.0 months in $\mathrm{EU}(\mathrm{p}<.01)$ and from 10.2 to 4.2 months in the US $(\mathrm{p}<.01)$. From 2012 to 2015 , patient decision was more frequently cited as a primary reason for choosing the first line DMT in EU $(6.8-10.3 \% ; \mathrm{p}<.01)$ and in the US (12.3$19.9 \% ; \mathrm{p}<.01)$. Additionally, preferring oral administration was also more frequently cited between 2012 and 2015 in EU (0.4-6.5\%; $<<.01)$ and the US (1.1-6.3\%; $<<.01)$. The percent citing oral administration as a primary reason for choosing the second line DMT increased significantly from $2.0 \%$ to $12.8 \%$ in $\mathrm{EU}(\mathrm{p}<.01)$ and from $1.3 \%$ to $18.2 \%$ $(\mathrm{p}<.01)$ in the US. Among patients who have recently (within past 3 months) discontinued treatment due to patient refusal, the percentage citing needle phobia as a reason for discontinuation decreased from $35.8 \%$ to $16.9 \%$ in $\mathrm{EU}$ $(\mathrm{p}=.02)$, and from $23.7 \%$ to $9.4 \%$ in the US, although this did not reach statistical significance in the US $(p=.10)$. (Table 2) 


\section{International Journal of Science and Research (IJSR) \\ ISSN (Online): 2319-7064}

Index Copernicus Value (2013): 6.14 | Impact Factor (2015): 6.391

Table 2: Initiation, switching, and discontinuation of DMTs

\begin{tabular}{|c|c|c|c|c|}
\hline & \multicolumn{2}{|c|}{ Europe } & \multicolumn{2}{|c|}{ USA } \\
\hline & 2012 & 2015 & 2012 & 2015 \\
\hline $\begin{array}{l}\text { Months from diagnosis to initiation of DMT }- \\
\text { Overall: }\end{array}$ & $\begin{array}{c}(\mathrm{n}=1730) \\
12.4\end{array}$ & $\begin{array}{c}(\mathrm{n}=1951) \\
8.0\end{array}$ & $\begin{array}{c}(\mathrm{n}=793) \\
10.0\end{array}$ & $\begin{array}{c}(\mathrm{n}=808) \\
4.6\end{array}$ \\
\hline Among patients on first line DMT & $\begin{array}{c}(\mathrm{n}=979) \\
13.6\end{array}$ & $\begin{array}{c}(\mathrm{n}=1144) \\
8.0\end{array}$ & $\begin{array}{c}(\mathrm{n}=462) \\
10.2\end{array}$ & $\begin{array}{c}(\mathrm{n}=405) \\
4.2\end{array}$ \\
\hline $\begin{array}{c}\text { Reasons for choosing the first line DMT: } \\
\text { Patient decision } \\
\text { Oral administration }\end{array}$ & $\begin{array}{c}(\mathrm{n}=979) \\
6.8 \% \\
0.4 \%\end{array}$ & $\begin{array}{c}(\mathrm{n}=1151) \\
10.3 \% \\
6.5 \%\end{array}$ & $\begin{array}{c}(\mathrm{n}=462) \\
12.3 \% \\
1.1 \%\end{array}$ & $\begin{array}{c}(\mathrm{n}=412) \\
19.9 \% \\
6.3 \%\end{array}$ \\
\hline $\begin{array}{c}\text { Reasons for choosing the second line DMT: } \\
\text { Patient decision } \\
\text { Oral administration }\end{array}$ & $\begin{array}{c}(\mathrm{n}=500) \\
3.6 \% \\
2.0 \%\end{array}$ & $\begin{array}{c}(\mathrm{n}=564) \\
4.1 \% \\
12.8 \%\end{array}$ & $\begin{array}{c}(\mathrm{n}=229) \\
8.3 \% \\
1.3 \%\end{array}$ & $\begin{array}{c}(\mathrm{n}=285) \\
9.8 \% \\
18.2 \%\end{array}$ \\
\hline $\begin{array}{l}\text { Reasons for discontinuing treatment: } \\
\text { Overall patient refusal } \\
\text { Patient refusal due to needle phobia }\end{array}$ & $\begin{array}{c}(\mathrm{n}=237) \\
22.4 \% \\
(\mathrm{n}=53) \\
35.8 \%\end{array}$ & $\begin{array}{c}(\mathrm{n}=281) \\
21.0 \% \\
(\mathrm{n}=59) \\
16.9 \%\end{array}$ & $\begin{array}{l}(\mathrm{n}=75) \\
50.7 \% \\
(\mathrm{n}=38) \\
23.7 \%\end{array}$ & $\begin{array}{c}(\mathrm{n}=73) \\
43.8 \% \\
(\mathrm{n}=32) \\
9.4 \%\end{array}$ \\
\hline
\end{tabular}

\section{Adoption of Oral DMTs}

In 2012 in EU, 11.3\% of currently treated patients were on an oral drug (fingolimod), and in the US, $9.2 \%$ of currently treated patients were on an oral drug $(8.7 \%$ on fingolimodand $0.5 \%$ on teriflunomide). In 2015, with fingolimod, teriflunomide, and dimethyl fumarateavailable as oral DMTs in both regions, the proportion of patients on an oral DMT increased to $35.6 \%$ in EU $(\mathrm{p}<.01)$ and $40.0 \%$ in US ( $p<.01)$. In EU, $14.5 \%$ were on fingolimod, $12.8 \%$ on dimethyl fumarate, and $8.3 \%$ on teriflunomide; in the US, $21.2 \%$ were on dimethyl fumarate, $11.2 \%$ were on fingolimod, and $7.6 \%$ were on teriflunomide. Correspondingly, the market shares of non-oralDMTs decreased during the same time period. (Table 3)
Adoption of oral DMTs increased the most in first line therapies in 2015, in comparison to 2012, mainly moving up the line from third line therapies. (Table 3 ) In 2012, 8.2\% of oral DMT users were on their first line DMT therapy (compared to $62.7 \%$ of non-oral DMT users, $\mathrm{p}<.01$ ) in EU; in US, $21.9 \%$ of oral DMT users were on their first line DMT therapy (compared to $61.9 \%$ of non-oral DMT users, $\mathrm{p}<.01$ ). In 2015, the proportion of oral DMT users who were on their first line DMT therapy increased to $40.3 \%$ in EU (compared to $69.0 \%$ of non-oral DMT users, $\mathrm{p}<.01$ ) and $34.7 \%$ in the US (compared to $61.1 \%$ of non-oral DMT users, $\mathrm{p}<.01$ ).

Table 3: Adoption of Oral DMTs

\begin{tabular}{|c|c|c|c|c|}
\hline & \multicolumn{2}{|c|}{ Europe } & \multicolumn{2}{|c|}{ USA } \\
\hline & 2012 & 2015 & 2012 & 2015 \\
\hline Number of currently treated patients & 1730 & 1959 & 793 & 815 \\
\hline Use of a non-oral DMT & $88.7 \%$ & $64.3 \%$ & $90.8 \%$ & $60.0 \%$ \\
\hline $\begin{array}{c}\text { Use of an oral DMT } \\
\text { fingolimod } \\
\text { teriflunomide } \\
\text { dimethyl fumarate }\end{array}$ & $\begin{array}{c}11.3 \% \\
11.3 \% \\
N A \\
N A\end{array}$ & $\begin{array}{c}35.6 \% \\
14.5 \% \\
8.3 \% \\
12.8 \%\end{array}$ & $\begin{array}{l}9.2 \% \\
8.7 \% \\
0.5 \% \\
N A\end{array}$ & $\begin{array}{c}40.0 \% \\
11.2 \% \\
7.6 \% \\
21.2 \%\end{array}$ \\
\hline $\begin{array}{c}\text { Use of an oral DMT, per treatment line } \\
\text { First line } \\
\text { Second line } \\
\text { Third + line }\end{array}$ & $\begin{array}{c}8.2 \% \\
42.1 \% \\
49.7 \%\end{array}$ & $\begin{array}{l}40.3 \% \\
41.2 \% \\
18.5 \%\end{array}$ & $\begin{array}{l}21.9 \% \\
39.7 \% \\
38.4 \%\end{array}$ & $\begin{array}{l}34.7 \% \\
47.5 \% \\
17.8 \%\end{array}$ \\
\hline $\begin{array}{c}\text { First line users - reasons for choosing } \\
\text { an oral DMT: } \\
\text { Patient decision } \\
\text { Oral administration } \\
\text { Efficacy for relapses }\end{array}$ & $\begin{array}{c}(\mathrm{n}=16) \\
\\
6.3 \% \\
12.5 \% \\
25.0 \%\end{array}$ & $\begin{array}{l}(\mathrm{n}=282) \\
\\
9.9 \% \\
26.2 \% \\
21.6 \%\end{array}$ & $\begin{array}{l}(\mathrm{n}=16) \\
\\
12.5 \% \\
31.3 \% \\
18.8 \%\end{array}$ & $\begin{array}{l}(\mathrm{n}=113) \\
17.7 \% \\
23.0 \% \\
22.1 \%\end{array}$ \\
\hline $\begin{array}{c}\text { Second line users - reasons for choosing } \\
\text { an oral DMT: } \\
\text { Patient decision } \\
\text { Oral administration } \\
\text { Efficacy for relapses } \\
\end{array}$ & $\begin{array}{c}(\mathrm{n}=82) \\
\\
0.0 \% \\
7.3 \% \\
40.2 \% \\
\end{array}$ & $\begin{array}{c}(\mathrm{n}=288) \\
\\
4.2 \% \\
25.0 \% \\
35.1 \% \\
\end{array}$ & $\begin{array}{l}(\mathrm{n}=29) \\
17.2 \% \\
10.3 \% \\
24.1 \% \\
\end{array}$ & $\begin{array}{c}(\mathrm{n}=155) \\
\\
8.4 \% \\
32.9 \% \\
23.2 \% \\
\end{array}$ \\
\hline $\begin{array}{c}\text { Third or subsequent line users - } \\
\text { reasons for choosing an oral DMT: } \\
\text { Patient decision } \\
\text { Oral administration } \\
\text { Efficacy for relapses }\end{array}$ & $\begin{array}{l}(\mathrm{n}=97) \\
\\
3.1 \% \\
4.1 \% \\
45.4 \%\end{array}$ & $\begin{array}{c}(\mathrm{n}=129) \\
\\
3.1 \% \\
21.7 \% \\
24.0 \%\end{array}$ & $\begin{array}{c}\mathrm{n}=28) \\
7.1 \% \\
17.9 \% \\
17.9 \%\end{array}$ & $\begin{array}{c}\mathrm{n}=58) \\
\\
3.4 \% \\
44.8 \% \\
17.2 \%\end{array}$ \\
\hline
\end{tabular}




\section{International Journal of Science and Research (IJSR) \\ ISSN (Online): 2319-7064 \\ Index Copernicus Value (2013): 6.14 | Impact Factor (2015): 6.391}

\section{Reasons for Choice of Oral DMT}

Among patients on first line therapy with an oral DMT, in 2012 , oral administration or patient decision were cited as the reasons for choosing the oral DMT in $18.8 \%$ of cases in EU and $43.8 \%$ of cases in the US; in 2015, this increased to $36.1 \%$ in the EU $(\mathrm{p}=.16)$ and remained stable at $40.7 \%$ in the US $(p=.82)$. Efficacy for relapses was cited approximately $21.9 \%$ of the time in EU and the US at both time points. (Table 3)

Among second line users of an oral DMT, efficacy for relapses was the most commonly cited reason for choosing the second line oral DMT in EU (40.2\% in 2012 and 35.1\% in 2015). In EU,oral administration or patient decision were cited $7.3 \%$ of the time in 2012 , and this increased to $29.2 \%$ in $2015(\mathrm{p}<.01)$. In the US, the proportion of second line oral DMT users that reported oral administration or patient decision increased from $27.5 \%$ in 2012 to $41.3 \%$ in 2015 $(\mathrm{p}<.01)$.

Similarly, among patients on third (or subsequent) line therapy with an oral DMT, in 2012, 45.4\%of patients in EU cited efficacy for relapses as the reason for switching to the oral therapy; oral administration or patient decision was cited for only $7.2 \%$ of these patients. In 2015 , the percent citing oral administration or patient decision increased to $24.8 \%(\mathrm{p}<.01)$, and the percent citing efficacy for relapses decreased to $24.0 \%(\mathrm{p}<.01)$. In the US, oral administration or patient decision outweighed efficacy for relapse at both time points (from $25.0 \%$ vs. $17.9 \%$ in 2012 , to $48.2 \%$ vs. $17.2 \%$ in 2015).

\section{Patient Disease Characteristics: Oral vs. Non-Oral DMT Users}

In 2012, the percentage of patients on oral DMTs who had moderate/severe disease severity (per physician clinical judgment) decreased from $74.8 \%$ to $45.5 \%$ in EU $(p<.01)$ and from $64.4 \%$ to $48.8 \%$ in the US $(p=.02)$. Rates of moderate/severe disease severity were similar among those using non-oral DMTsat both time points $(47.2 \%$ and $45.6 \%$ in EU, and $46.3 \%$ and $43.4 \%$ in US, in 2012 and 2015, respectively; both non-significant). (Figure 1)

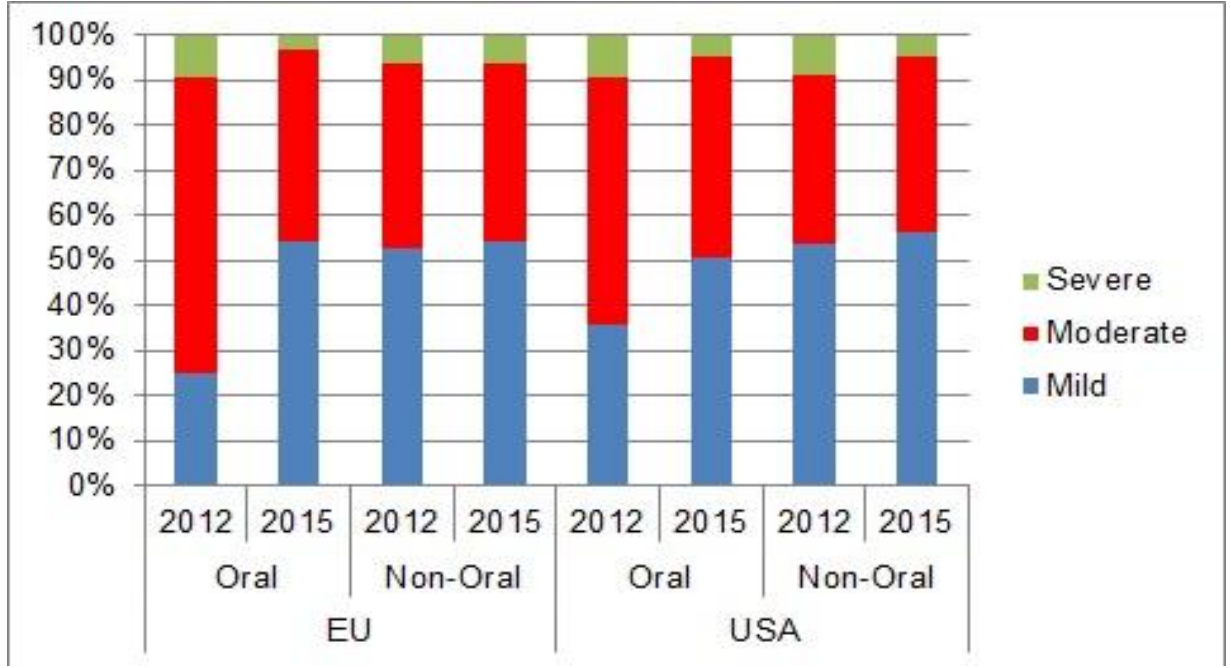

Figure 1: Physician Global Assessment of Disease Severity

Mean Expanded Disability Status Scale (EDSS) scores for oral DMT users decreased from 3.6 to 2.7 in EU $(p<.01)$ and from 3.2 to 3.0 in US (NS; $p=.52$ ), from 2012 to 2015 , while
EDSS scores remained stable for non-oral DMT users (2.8 in EU and 2.7 in US in 2012 and 2015). (Figure 2)

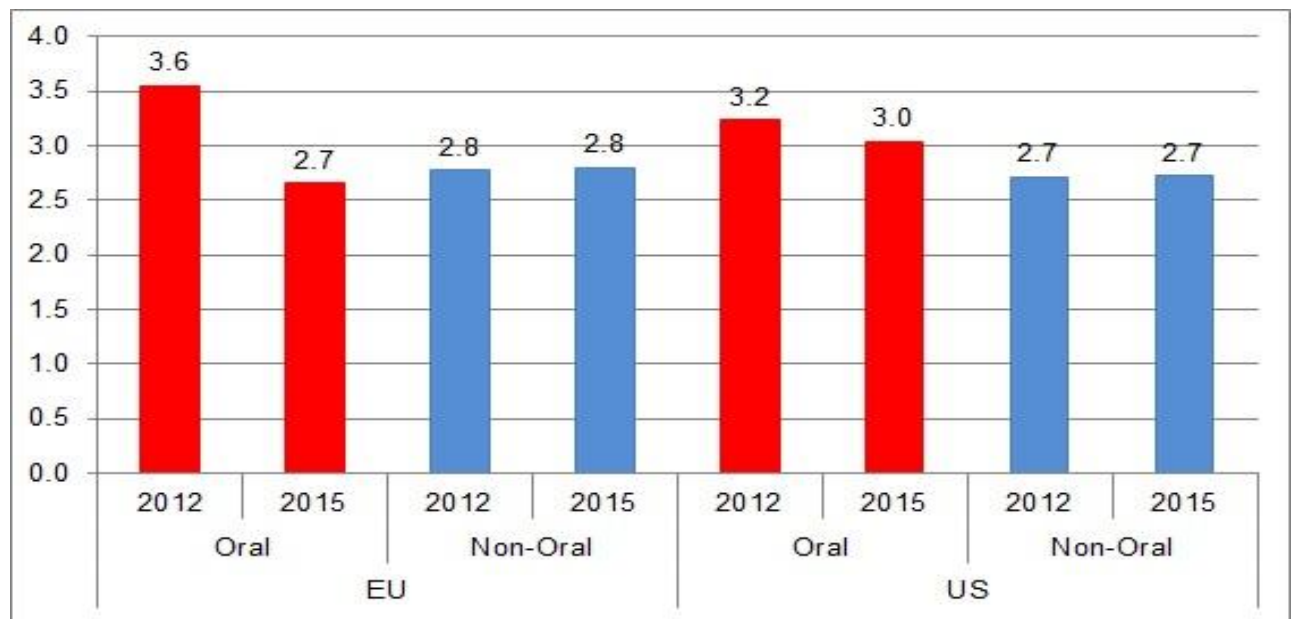

Figure 2: Mean Expanded Disability Status Scale (EDSS) Scores 


\section{International Journal of Science and Research (IJSR) \\ ISSN (Online): 2319-7064 \\ Index Copernicus Value (2013): 6.14 | Impact Factor (2015): 6.391}

Note: Scores range from 0 to 10; higher scores indicate greater disability

The average number of relapses suffered by patent in last 12 months among oral DMT usersvs. non-oral DMT users were 1.09 vs. 0.61 (in 2012) and 0.87 vs. 0.62 (in 2015) in the EU, and 0.81 vs. 0.58 and 0.83 vs. 0.65 in the US.

\section{Discussion}

While nearly four in 10 patients studied in 2015 were currently taking an oral DMT for their multiple sclerosis, the market is still dominated by non-oral DMTs. Between 2012 and 2015, largest increase in oral DMTs were observed in first line therapy, with the corresponding decrease in use in third line therapy. Oral administration and patient decision appear to be of greater influence on choice of DMT in the US than in EU. A lower, albeit, exponentially increasing, proportion of patients on their first line DMT were using an oral DMT than patients on a DMT as a subsequent line of therapy, suggesting that oral DMTs may not have been considered the treatment of choice for first line DMT therapy initially (when they are first introduced) either as a function of physicians choice/preference or payer restrictions (tied to formulary position).Patient disease severity, EDSS scores and average number of relapses in last 12 months among those on oral DMTs (versus those on nonoral DMTs) in 2012 is reflective of initial use of oral DMTs among patients with severe (or refractory) disease, while 2015 data is indicative of the broader (increasing) adoption of oral DMTs among MS patients as the difference in patient characteristics become less conspicuous.

Treatment guidelines for MS do not offer an algorithmic or "one-size-fits-all" solution, but rather stress the importance of personalized medicine. A 2015 consensus document developed by the Multiple Sclerosis Coalition in the US asserts that multiple complex factors should be taken into account when making treatment decisions, including the mechanism of action and response, contraindications, risk tolerance, route of delivery, side effects, tolerability, and adherence. Thus, the coalition emphasizes that the full range of treatment options should be available to all patients. The coalition also recommends early initiation of a DMT following a diagnosis of relapsing MS, with treatment only changing for medically appropriate reasons, such as suboptimal response, intolerable side effects, poor adherence, or availability of a more appropriate treatment option [8]. The addition of oral DMTs to the armamentarium of treatment options to manage MS patients has been welcomed by HCPs globally, as evident from this research on oral DMT adoption. The choice of specific individual DMTs and establishment of patient profiles that may most benefit from each one may require additional evidence.

The proportion of patients for whom oral administration or patient decision were cited as the reasons for choosing the oral DMT as first line therapy increased in the EU $(18.8 \%$ vs. $36.1 \%$ ), while it remained stable in the US $(43.8 \%$ vs. $40.7 \%$ ) between 2012 and 2015; citation of these reasons among patients initiating on second line therapy also increased over this time period. Interestingly, among those discontinuing DMTs, ,patient refusal ${ }^{\text {ee }}$ has remained as a key reason for discontinuation in the EU (approx. 20\%) and US (approx. 40-50\%), indicating an additional dimension of patient influence in treatment decisions. These observed patterns may be reflective of an effort by the HCP community in engaging patients in treatment decisions and offer convenient regimen so as to positively influence patient adherence and long-term outcomes [9]; however, actual impact of observed treatment patterns on patient behaviour and outcomes warrant further scrutiny.

Restrictions in access to certain DMTs only after failure of first-line therapy may further complicate decision-making in real-world settings [10].As long-term safety and efficacy data become available for the oral DMTs and comparative effectiveness of treatments becomes known, it may aid therapeutic optimization and prove beneficial for patient outcomes.

\section{Strengths \& Limitations}

Strengths of this study include the large sample size across countries. It should be noted, however, that the patient management practices reported in this study represent only the practices of the HCPs who participated in this study and may vary from those of non-participating HCPs. Further analysis is warranted to delineate the treatment trends per MS type. All data, including reasons for switching DMTs, are reported by the treating HCPs, and this may vary from patient self-report. Further, careful interpretation of data is warranted in light of the fact that the availability of drugs (especially, the oral DMTs) and the nature of reimbursement hurdles associated with each of them in the studied countries may have influenced the observed trends.

\section{Conclusion}

Use of oral DMTs for multiple sclerosis became much more common between 2012 and 2015, due to improved availability and, in part, to patient choice and preference for an oral DMT. Oral DMT adoption increased the most in first line therapy in 2015, moving up from third line therapy positioning predominantly observed in 2012. During the same time period, proportion of patients with higher disease severity and disability level decreased (from 2012 to 2015) among those on oral DMTs. Non-oral DMTs still have a higher market share and oral DMTs are not the treatment of choice yet in first line therapy, despite the likelihood of increased adherence due to the reduced treatment burden. As patients and clinicians become more experienced with oral DMTs over time, future demonstration of long-term outcomes and comparative effectiveness of treatment options may influence appropriate therapy choice to benefit patients.

\section{Conflict of Interest}

Authors declare no conflict of interest related to this subject matter. 


\section{References}

[1] Wootla B, Eriguchi M, Rodriguez M. Is multiple sclerosis an autoimmune disease? Autoimmune Dis. 2012;2012:969657.

[2] Kamm CP, Uitdehaag BM, Polman CH. Multiple sclerosis: current knowledge and future outlook. Eur Neurol. 2014 Jul 30;72(3-4):132-141.

[3] Narayanan S, O'Meara P, White J, et al. Characteristics of patients with relapsing remitting multiple sclerosis taking injectable and oral disease modifying treatments in the United States. Value Health. 2014;17(7): A4045.

[4] Patti F. Optimizing the benefit of multiple sclerosis therapy: the importance of treatment adherence. Patient Prefer Adherence. 2010; 4:1-9.

[5] Verdun di Cantogno E, Russell S, Snow T. Understanding and meeting injection device needs in multiple sclerosis: a survey of patient attitudes and practices. Patient Prefer Adherence. 2011;5:173-80.

[6] Devonshire V, Lapierre Y, Macdonell R, et al. The Global Adherence Project (GAP): a multicenter observational study on adherence to disease-modifying therapies in patients with relapsing-remitting multiple sclerosis. Eur J Neurol. 2011;18(1):69-77.

[7] Yermakov S, Davis M, Calnan M, Fay M, Cox-Buckley B, Sarda S, Duh MS, Iyer R. Impact of increasing adherence to disease-modifying therapies on healthcare resource utilization and direct medical and indirect work loss costs for patients with multiple sclerosis. J Med Econ. 2015 Sep;18(9):711-20.

[8] Multiple Sclerosis Coalition. The use of diseasemodifying therapies in multiple sclerosis: Principles and current evidence. March 2015. Accessed 22 October 2015 , from: http://www.nationalmssociety.org/getmedia/5ca284d3fc7c-4ba5-b005ab537d495c3c/DMT_Consensus_MS_Coalition_color

[9] Lorefice L, Fenu G, Frau J, Coghe GC, Marrosu MG, Cocco E. Oral agents in multiple sclerosis. Antiinflamm Antiallergy Agents Med Chem. 2015;14(1):15-25.

[10]Dörr J, Paul F. The transition from first-line to secondline therapy in multiple sclerosis. Curr Treat Options Neurol. 2015 Jun;17(6):354. 